\title{
The nature of the change of the surface temperature of the workpiece during hot rolling of pipe steel
}

\author{
Vladimir Nekit $^{1}$, Sergey Platov ${ }^{1, *}$, and Maksim Krasnov ${ }^{2}$ \\ ${ }^{1}$ Nosov Magnitogorsk State Technical University, Lenin Street, 38, Magnitogorsk city, Chelyabinsk \\ Region, Russian Federation, 455000 psipsi@mail.ru \\ ${ }^{2}$ PJSC "MMK", Magnitogorsk, Russia
}

\begin{abstract}
The article is devoted the experimental studies of deformation and temperature parameters of rolling the pipe steel on the rolling mill 5000 PJSC "MMK". Knowledge of the regularities of the change in the surface temperature of work piece during hot rolling under the conditions of thermo mechanical deformation processes is of great theoretical and practical importance. The temperature conditions determine the energy and force parameters of rolling, as well as the mechanical properties and microstructure of the finished products. The experimental rolling was carried out in two stages: roughing at 6 passes at a temperature of 1050$900^{\circ} \mathrm{C}$ and finishing at $18-20$ passes at a temperature below the start of the phase transformation of $900^{\circ} \mathrm{C}$. The finishing rolling has been carried out in a two-phase region at the stage of polymorphic transformation in the steel. Significant differences in the nature of temperature changes at different stages of rolling are revealed.
\end{abstract}

\section{Introduction}

To increase the impact toughness and other mechanical properties in the production of pipe steel controlled low-temperature rolling is used. The use of regulated between deformation cooling allows realizing the mode of thermo mechanical processing and two-phase rolling during the finishing stage of deformations, which significantly expand the capabilities of the rolling mill in obtaining high consumer properties of products [1-7].

Flat rolling of high-strength low-alloy steels at low metal temperature is associated with high deformation resistance and, consequently, with high values of metal pressure on the rolls and with high values of the torques perceived by the electric motors. The permissible rolling mill force (120000 MN) and the torque of the electric motors of the rolling mill 5000 allow rolling the metal at high loads.

Knowledge of the patterns of change in temperature of the rolled sheet in the hot rolling process in conditions of thermo-mechanical deformation processes is of great theoretical and practical importance. Temperature conditions determine the energy-power parameters of rolling, as well as mechanical properties and microstructure of the finished product.

\footnotetext{
*Corresponding author: psipsi@mail.ru
} 


\section{Methodology}

The rolling mill technology process analysis system operates with two main electronic documents containing the rolling process information [8]. To check the reliability of the data included in the passport, the information stored in the level 1 database of the automated process control system was used. This information is initial one; it is formed by processing of data of the first level on the basis of specialized algorithms.

Experimental study of deformation and temperature parameters at rolling of pipe steel at the rolling mill 5000 PJSC "MMK" were conducted. Flat rolling was carried out in two stages; roughing rolling at 6 passes at a temperature of $1050-900^{\circ} \mathrm{C}$ and finishing rolling at 18-20 passes at a temperature below the beginning of the phase transformation of $900^{\circ} \mathrm{C}$.. Three experimental thermo mechanical rolling modes were selected for the study. They differed one from another by the temperature of the beginning of deformation in the finishing stage of rolling. Rolling mode 1 had an initial temperature of $900^{\circ} \mathrm{C}$, corresponding to the beginning of the phase transformation, the other (mode 2) $-800^{\circ} \mathrm{C}$, corresponding to the middle of the phase transformation interval. According to the mode 3 , plastic deformation is beginning at the lowest temperature level of the phase transformation interval, at a temperature of $750^{\circ} \mathrm{C}$. The temperature conditions of rolling at the roughing stage are not considerably differed (Fig 2). To control the sheet thickness in the line of rolling mill ultrasonic thickness gauge $0.7 \mathrm{MG} 26$ with a measuring range of $0.5-500 \mathrm{~mm}$ is used for. All three experimental work pieces were rolled in one mode of deformation. The estimation of deformation degree in the passages was carried out by the cumulate total. The graph of the accumulated degree of deformation under the rolling is shown in figure 1.

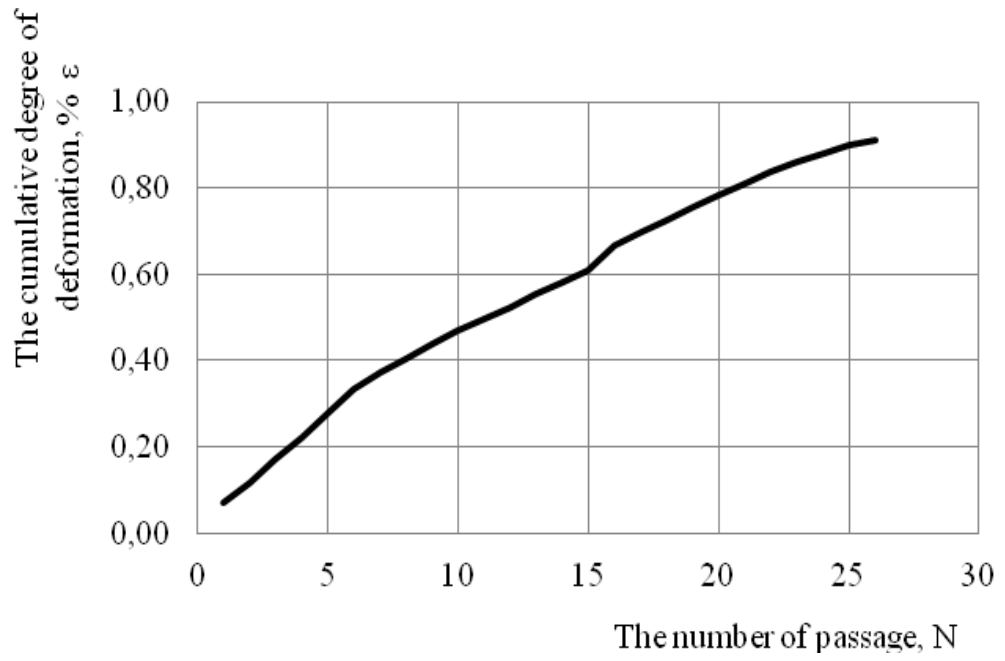

Fig. 1. Change of cumulative degree of deformation during experimental rolling.

The temperature of the strip surface was adopted as thermodynamic characteristic of the deformation process on the hot rolling mill. Infrared pyrometers of spectral relation of R1 "Land" 600-1600, controllers LMT Technics was used for the continuous measurement of temperature in the rolling process. 


\section{Results and discussions}

Significant differences in the nature of temperature changes at different stages of rolling are revealed. At the roughing stage, which occurs at the temperatures above the phase transformation temperature of $1200-900^{\circ} \mathrm{C}$, there is a steady decline in the rolling temperature (Fig.2). Despite the heat release during the plastic deformation of the rolls, there is an intense loss of heat due to different thermal processes: heat transfer by radiation and convection, thermal conductivity in rolls, roller rolls, etc. The linear statistical dependence of temperature on the total degree of deformation in the rolling process for all three modes is very tight, which is confirmed by a high correlation coefficient of 0.97 . In addition, these dependencies have almost the same angle of inclination of the trend line $134-142^{\circ} \mathrm{C}$. (Table 1$)$.

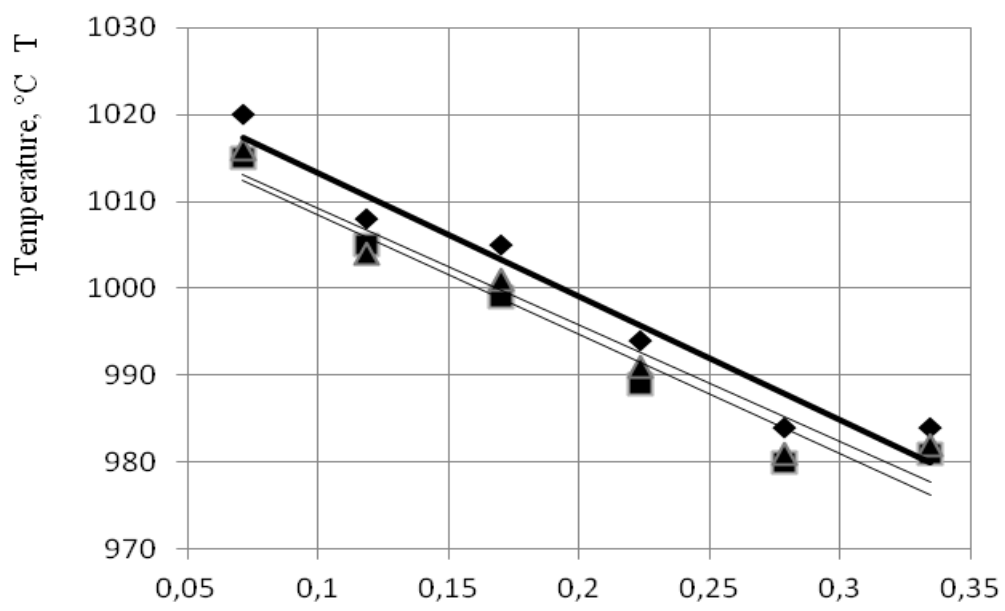

The cumulative degree of deformation, $\% \varepsilon$

Fig. 2. Temperature change at the roughing stage of rolling with the growth of the total degree of deformation:

Table 1. Statistical characteristics of temperature changes at the roughing stage of rolling

\begin{tabular}{|l|c|c|c|}
\hline & Mode1 & Mode 2 & Mode 3 \\
\hline Correlation coefficient, $r$ & $-0,97$ & $-0,97$ & $-0,97$ \\
\hline The slope of the trend line & $-141,7$ & $-137,27$ & $-134,08$ \\
\hline
\end{tabular}

At the finishing stage of rolling, this takes place at the temperatures below the phase transformation temperature of $900-750^{\circ} \mathrm{C}$., there is an increase in temperature due to energy release at plastic deformation of the metal and the thermal effect of phase transformation. The angles of the trend lines for all three modes of rolling are presented in the table. 2. The intensity of the growth of the surface temperature of the work piece substantially depends on the temperature of the beginning of plastic deformation in the two-phase region of Fig. 2 . The highest intensity of growth of the work piece surface temperature corresponds to the rolling mode 3 , which has a minimum starting temperature of plastic deformation at the stage of finishing rolling $750^{\circ} \mathrm{C}$. When rolling at mode of deformation 1 there is a maximum deviation of the measurement results near the trend line. 


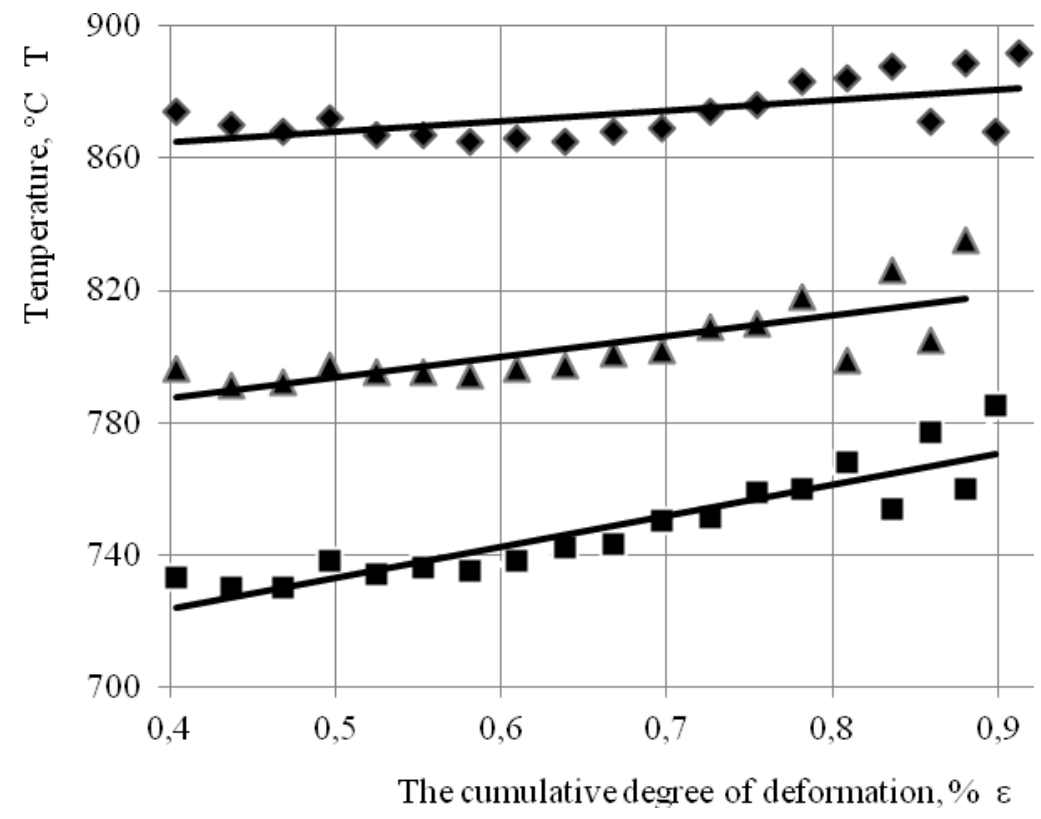

Fig. 3. Temperature change at the final stage of rolling with the growth of the total degree of deformation: $\boldsymbol{\Delta} \Delta \boldsymbol{\Delta}$ mode 1, mode 3 .

Table 2. Statistical characteristics of temperature changes at the finishing stage of rolling

\begin{tabular}{|l|c|c|c|}
\hline & Mode1 & Mode 2 & Mode3 \\
\hline Correlation coefficient, $r$ & 0,61 & 0,78 & 0,91 \\
\hline The slope of the trend line & 32,28 & 63,1 & 93,77 \\
\hline
\end{tabular}

\section{Summary}

Experimental studies of the deformation and temperature parameters of rolling of pipe steel at the rolling mill 5000 PJSC "MMK" were conducted. Rolling was carried out in two stages: roughing rolling for 6 passes at a temperature of $1050-900^{\circ} \mathrm{C}$ and finishing rolling for 18-20 passes at a temperature below the beginning of the phase transformation of $900^{\circ} \mathrm{C}$. Significant differences in the nature of temperature changes at different stages of rolling are revealed. At the roughing stage, which occurs at temperatures above the phase transformation temperature of $1200-900^{\circ} \mathrm{C}$., a steady decrease in the rolling temperature was revealed. At the final rolling stage, which occurs at temperatures below the phase transformation temperature of $900-750^{\circ} \mathrm{C}$., there is an increase in the surface temperature of the roll. The intensity of increase of the work piece surface temperature significantly depends on the starting temperature of the plastic deformation in the two-phase region. Temperature conditions of deformation can be used in the theoretical analysis of the rolling process. 


\section{References}

1. S.I. Platov, V.A. Nekit, N.N. Ogarkov, O.S. Zhelezkov, Research of technology of the accelerated cooling of a rod on a wire rolling mill, Processing of solid and layered materials, No. 2 (45), pp. 45-48 (2016)

2. A.R. Gareev, A.S. Murikov, S.I. Platov, V.N. Urtsev, A.V. Shmakov, Analysis and experimental verification of the model heat release during phase transformations, Production of rolled products, No. 2, pp. 30-34 (2015)

3. A.R. Gareev, A.S. Murikov, S.I. Platov, V.N. Urtsev, A.V. Shmakov, Development of a mathematical model of heat release during phase transformations for industrial applications, Production of rolled products, No. 7, pp. 20-26 (2014)

4. S.I. Platov, N.N. Ogarkov, V. A. Nekit, Improving the controlled cooling of wire rod after rolling in the finishing block of stands, Proceedings: Materials Engineering and Technologies for Production and Processing II Editors: A. A. Radionov, G.G. Mikhailov, D.A. Vinnik, pp. 620-624 (2016)

5. S.I. Platov, V.A. Nekit, E.Yu. Zvyagina, D.V. Terentyev, Improvement of the temperature regime of the rolls due to improvement of cooling during the rolling process, Proceedings: Perspective materials and technologies, Materials of the international Symposium, In 2 parts . Edited by V.V. Rubanik, pp. 247-250 (2017)

6. S.I. Platov, V.A. Nekit, N.N. Ogarkov, Mathematical modelling of cooling process of metal during rolling on a small-grade wire mill, Proceedings: Perspective materials and technologies. Materials of the international Symposium, In 2 parts. Edited by V.V. Rubanik, pp. 251-253 (2017)

7. S.I. Platov, V.A. Nekit, N.N. Ogarkov, Mathematical modelling of cooling process of metal during rolling on a small-grade wire mill, Proceedings: Advanced materials and technologies. V.A. Andreev, A.A. Antanovich, S.S. Aplesnin, A.A. Baturin, M.A. Belotserkovsky, A.A. Vikarchuk, G.A. Volkov, A.S. Volynets, Yu.N. Vyunenko, R.G. Galin, A.V. Galligo, V.N. Grishkov, A.P. Gutev, A.M. Rodent, N.N. Gryzunova, R.R. Dema, A.A. Dzhejora, A.M. Zhivulko, A.G. Zholnin, E.Yu. Zvyagina, etc.]. Vitebsk, pp 295-310 (2017)

8. F.V. Kaptsan, A.V. Fomichev, A.A. Pronin, A.A. Voznesensky, Management system for technology on the base of the technology data warehouse, Technology improvement at PJSC "MMK": Proceedings of the Central lab. PJSC "MMK", Magnitogorsk, Vol.10, pp. 378-389 (2006) 